\title{
STORY COMPLETION: A TECHNIQUE IN TEACHING SPEAKING
}

\author{
Salmon J Hukom ${ }^{1}$ \\ sjhukom@yahoo.com
}

\begin{abstract}
In general, to achieve goals in teaching and learning the teachers can prepare appropriate strategy. This paper discusses a teaching and learning medium of speaking through story completion technique. By using this technique, it can be one of the exciting activities for motivating students in learning English confidently, especially speaking. The technique has activities which enable students to convey their ideas and all students obtain the same opportunities to speak at every meeting. The activities are oral activities that make student relax, happy and fun. The technique equips the students who have good English grammar and have sufficient vocabulary to explore their ideas in speaking. It does not mean that Story Completion technique cannot be used for students who have low English competence. The English teachers could manipulate the class by providing students with vocabularies of certain topic and tenses they will use in their speaking before running the meeting with this technique.
\end{abstract}

Keywords: Story Completion, Speaking, Teaching Speaking

\section{Introduction}

To be able to communicate with other people, speaking ability is indipensable. Therefore, teachers who teach English as a foreign language (EFL) always put their attention on enriching students' vocabulary as well as grammar since these two aspects, however, are different with students' mother tongues. Therefore, Thornbury (2007) said that it is important to develop learners' sociocultural knowledge that is "the culturally embedded rules of social behaviour" and their linguistic knowledge, which includes discourse and speech act knowledge, and know- ledge of the grammar, vocabulary and phonology of the target language.

Other factors that influence students' speaking ability according to Ur (1995) are students' attitude and personalities. There are some factors like 1) inhibition - fear of making mistakes, losing face, criticism; shyness; 2) nothing to say - learners have problems with finding motives to speak, formulating opinions or relevant comments; 3) low or uneven participation - often caused by the tendency of some learners to dominate in the group; 4) mother-tongue use particularly common in less disciplined or lessmotivated classes, learners find it easier or more natural to expressthemselves in their native language.

\footnotetext{
${ }^{1}$ Salmon James Hukom is Lecturer at English Department, Pattimura University, Ambon - Maluku Indonesia
} 
Besides that the role of teachers is very important in all aspects of teaching and learning process. The teachers are not only teaching the class but can be a mother/father/friend to give motivation for students to study his/her subject in this case English. As states by Lightbrown and Spada (2006) that teachers also have more infuence on these behaviours and the motivation they represent than on students' reasons for studying the second language ortheir attitudes toward the language and its speakers. Teachers can make a positive contribution to students' motivation to learn if classrooms are places that students enjoy coming to because the content is interesting and relevant to their age and level of ability, the learning goals are challenging yet manageable and clear, and the atmosphere is supportive.

\section{What is Speaking}

According to Chaney in Kayi (2006), speaking is the process of building and sharing meaning through the use of verbal and non-verbal symbols, in a variety of contexts". It means that speakers and their partners in speaking can use verbaland non verbal in convey meaning in speaking.

Speaking is a crucial part of second language learning and teaching. Despite its importance, for many years, teaching speaking has been undervalued and English language teachers have continued to teach speaking just as a repetition of drills or memorization of dialogues. However, today's world requires that the goal of teaching speaking should improve students' communicative skills, because, only in that way, students can express themselves and learn how to follow the social and cultural rules appropriate in each communicative circumstance. In order to teach second language learners how to speak in the best way possible, some speaking activities are provided below, that can be applied to ESL and EFL classroom settings, together with suggestions for teachers who teach oral language.

\section{What Makes Speaking Difficult}

Like other skills, speaking also has specific characteristics that make it difficult. Nunan (2003) mentioned some difficulties that can be obstacles in speaking.

1. Clustering

Fluent speech is phrasal, not word by word. Learners can organize their output both cognitively and physically (in breath groups) through such clustering.

2. Redundacy

The speaker has an opportunity to make meaning clearer through the redundancy of language. Learners can capitalize on this feature of spoken language.

3. Reduced forms

Contractions, elisions, reduced vowels, etc., all form special problems in teaching spoken english students who do not learn colloquial contractions can sometimes develop a stilted bookish quality of speaking that in turn stigmatizes them.

4. Performance Variables 
One of the advantages of spoken language is that the process of thinking of young speak allows you to manifest a certain number of performance hesitations, pauses, backtracking, and corrections. Learners can actually be taught how to pause and hesitate. For example, in english our "thinking time" is not silent; we insert certain "fillers" such as uh, um, well, you know, i mean, like, etc. One of the most salient differences between native and nonnative speakers of a language is in their hesitation phenomena.

5. Colloquial Language

Make sure your students are reasonably well acquainted with the words, idioms, and phrases of colloquial language and that they get practice in producing these forms.

6. Rate of delivery

Another salient characteristic of fluency is rate of delivery. One of your task in teaching spoken english is to help learners achieve an acceptable speed along with other attributes of fluency.

7. Stress, rhythm, and intonation

This is the most important characteristic of english pronunciation, as will be explained below. The stress-timed ryhthm of spoken english and its patterns convey important messages.

8. Interaction

As noted in the previous section, learning to produce waves of language in a vacuum-without interlocutors-would rob speaking skill of its richest component: the creativity of conversational negotiation.

\section{Factors Causing Speaking are Difficult for EFL Learners}

In communication, speaking plays important role besides writing. It cannot be denied that speaking seems complicated for EFL students. In line with this Zhang in Al Hosni (2014) said that speaking remains the most difficult skill to master for the majority of English learners, and they are still incompetent in communicating orally in English.

In addition, Rababa'h in Al Hosni (2014) pointed out that there are many factors that cause difficulties in speaking English among EFL learners. Some of these factors are related to the learners themselves, the teaching strategies, the curriculum, and the environment. For example, many learners lack thenecessary vocabulary to get their meaning across, and consequently, they cannot keep the interaction going.Inadequate strategic competence and communication competence can be another reason as well for not being able to keep the interaction going. Some learners also lack the motivation to speak English. They do not see a real need to learn or speak English. Actually -motivation is the crucial force which determines whether a learner embarks in a task at all, how much energy he devotes to it, and how long he preservers\| (Littlewood in Al Hosni, 2014). The development of communicative skills can only take place if learners have the motivation and opportunity to express their own identity and relate with the people around them (Littlewood in Al Hosni, 2014).

Teaching strategies also contribute to this problem as they are inadequate, and they do not put emphasis on speaking, which results in a meagre development 
of this skill. Besides, vocabulary items are taught in isolation, and listening materials are not used by the majority of schoolteachers because of the large number of teachers compared with the number of cassettes available. Teachertraining programs were found to be not very successful in changing the teachers' methodology (Rababa'ah in Al Hosni, 2014).

Littlewood in Al Hosni (2014) argued that some teachers use L1 for class management. Nevertheless, this can be another factor that contributes to the problem of speaking difficulties. This is because using L1 means sacrificing valuable opportunities for well-motivated foreign use. In addition, it tends to devalue the foreign language as a vehicle for communication.Learners see it as allocated to communicatively nonessential domains such as drills or dialogue practice, while the mother tongue remains the appropriate medium for discussing matters of immediate importance.Another main reason for other teachers to use L1 is vocabulary and grammar.Although their attitudes are of disagreement with $\mathrm{L} 1$, this is not reflected in their practice (Al-Busaidi in Al Hosni, 2014).

\section{Teaching Speaking}

Generally, the function of language is for communication. Therefore, teaching foreign language like English is also emphasized on facilitating the students to communicate like in oral (speaking) and written (writing). As stated by Al-Sibai in Al Hosni (2014) saying that the use of English as a second language (ESL) or foreign language (EFL) in oral communication is, withouta doubt, one of the most common but highly complex activities necessary to be considered when teaching the English language especially because we - live at a time where the ability to speak English fluently has become a must, especially who want to advance in certain fields of human endeavor. Furthermore, Haozang in Al Hosni states that the focus of teaching speaking, of course, is to improve the oral production of the students. Therefore, language teaching activities in the classroom should aim at maximising individual language use.

In line with the statements above, Nunan in Kayi (2006) states that teaching speaking means teach ESL/EFL learners to:

- Produce the English speech sounds and sound patterns

- Use word and sentence stress, intonation patterns and the rhythm of the second language.

- Select appropriate words and sentences according to the proper social setting, audience, situation and subject matter.

- Organize their thoughts in a meaningful and logical sequence.

- Use language as a means of expressing values and judgments.

- Use the language quickly and confidently with few unnatural pauses, which is called as fluency.

\section{Strategies to Promote Speaking}

Many strategies are suggested to apply in order to promote speaking activities. Kayi (2006) suggests the following strategies:

\section{Discussions}


After a content-based lesson, a discussion can be held for various reasons. The students may aim to arrive at a conclusion, share ideas about an event, or find solutions in their discussion groups. Before the discussion, it is essential that the purpose of the discussion activity is set by the teacher. In this way, the discussion points are relevant to this purpose, so that students do not spend their time chatting with each other about irrelevant things. For example, students can become involved in agree/disagree discussions. In this type of discussions, the teacher can form groups of students, preferably 4 or 5 in each group, and provide controversial sentences like "people learn best when they read vs. people learn best when they travel". Then each group works on their topic for a given time period, and presents their opinions to the class. It is essential that the speaking should be equally divided among group members. At the end, the class decides on the winning group who defended the idea in the best way. This activity fosters critical thinking and quick decision making, and students learn how to express and justify themselves in polite ways while disagreeing with the others. For efficient group discussions, it is always better not to form large groups, because quiet students may avoid contributing in large groups. The group members can be either assigned by the teacher or the students may determine it by themselves, but groups should be rearranged in every discussion activity so that students can work with various people and learn to be open to different ideas. Lastly, in class or group discussions, whatever the aim is, the students should always be encouraged to ask questions, paraphrase ideas, express support, check for clarification, and so on.

\section{Role Play}

One other way of getting students to speak is role-playing. Students pretend they are in various social contexts and have a variety of social roles. In role-play activities, the teacher gives information to the learners such as who they are and what they think or feel. Thus, the teacher can tell the student that "You are David, you go to the doctor and tell him what happened last night, and..." (Harmer, 1984)

\section{Simulations}

Simulations are very similar to role-plays but what makes simulations different than role plays is that they are more elaborate. In simulations, students can bring items to the class to create a realistic environment. For instance, if a student is acting as a singer, she brings a microphone to sing and so on. Role plays and simulations have many advantages. First, since they are entertaining, they motivate the students. Second, as Harmer (1984) suggests, they increase the selfconfidence of hesitant students, because in role play and simulation activities, they will have a different role and do not have to speak for themselves, which means they do not have to take the same responsibility.

\section{Information Gap}

In this activity, students are supposed to be working in pairs. One student will have the information that other partner does not have and the partners will 
share their information. Information gap activities serve many purposes such as solving a problem or collecting information. Also, each partner plays an important role because the task cannot be completed if the partners do not provide the information the others need. These activities are effective because everybody has the opportunity to talk extensively in the target language.

\section{Brainstorming}

On a given topic, students can produce ideas in a limited time. Depending on the context, either individual or group brainstorming is effective and learners generate ideas quickly and freely. The good characteristics of brainstorming is that the students are not criticized for their ideas so students will be open to sharing new ideas.

\section{Storytelling}

Students can briefly summarize a tale or story they heard from somebody beforehand, or they may create their own stories to tell their classmates. Story telling fosters creative thinking. It also helps students express ideas in the format of beginning, development, and ending, including the characters and setting a story has to have. Students also can tell riddles or jokes. For instance, at the very beginning of each class session, the teacher may call a few students to tell short riddles or jokes as an opening. In this way, not only will the teacher address students' speaking ability, but also get the attention of the class.

\section{Interviews}

Students can conduct interviews on selected topics with various people. It is a good idea that the teacher provides a rubric to students so that they know what type of questions they can ask or what path to follow, but students should prepare their own interview questions. Conducting interviews with people gives students a chance to practice their speaking ability not only in class but also outside and helps them becoming socialized. After interviews, each student can present his or her study to the class. Moreover, students can interview each other and "introduce" his or her partner to the class.

\section{Reporting}

Before coming to class, students are asked to read a newspaper or magazine and, in class, they report to their friends what they find as the most interesting news. Students can also talk about whether they have experienced anything worth telling their friends in their daily lives before class.

\section{Picture Narrating}

This activity is based on several sequential pictures. Students are asked to tell the story taking place in the sequential pictures by paying attention to the criteria provided by the teacher as a rubric. Rubrics can include the vocabulary or structures they need to use while narrating.

\section{Picture Describing}


Another way to make use of pictures in a speaking activity is to give students just one picture and having them describe what it is in the picture. For this activity students can form groups and each group is given a different picture. Students discuss the picture with their groups, then a spokesperson for each group describes the picture to the whole class. This activity fosters the creativity and imagination of the learners as well as their public speaking skills.

\section{Find the Difference}

For this activity students can work in pairs and each couple is given two different pictures, for example, picture of boys playing football and another picture of girls playing tennis. Students in pairs discuss the similarities and/or differences in the pictures.

\section{Story Completion}

This is a very enjoyable, whole-class, free-speaking activity for which students sit in a circle. For this activity, a teacher starts to tell a story, but after a few sentences he or she stops narrating. Then, each student starts to narrate from the point where the previous one stopped. Each student is supposed to add from four to ten sentences. Students can add new characters, events, descriptions and so on.

\section{Teaching Speaking Through Story Completion}

According to Ghiabi (2014), now many linguistics and EFL teachers agree on that students learn to speak in the secondlanguage by "interacting". Communicative language teaching and collaborative learning servebest for this aim. Communicative language teaching is based on real-life situations that requirecommunication. By using this method in EFL classes, students will have the opportunity ofcommunicating with each other in the target language. In brief, EFL teachers should create aclassroom environment where students have real-life communication, authentic activities, andmeaningful tasks that promote oral language. This can occur when students collaborate in groupsto achieve a goal or to complete a task.

Story completion is a very enjoyable, whole-class, free-speaking activity for which students sit ina circle. For this activity, a teacher starts to tell a story, but after a few sentences he or she stopsnarrating. Then, each student starts to narrate from the point where the previous one stopped.Each student is supposed to add from four to ten sentences. Students can add new characters, events, descriptions and so on.

This technique helps students' speaking skills improving. In this type of teaching studentscreativity also improve; in contrast to story retelling, in this technique students must usevocabulary of their own. This is an open task and it is students who manage the story and try tocomplete it.

There are a number of ways in which story completion can enhance intercultural understandingand communication. Stories can:

- allow students to explore their own cultural roots

- allow students to experience diverse cultures

- enable students to empathize with unfamiliar people/places/situations 
- offer insights into different traditions and values

- help students understand how wisdom is common to all peoples/all cultures

- offer insights into universal life experiences

- help students consider new ideas

- reveal differences and commonalties of cultures around the world

There are other benefits of story completion such as stories promote a feeling of well-being andrelaxation, increase children's willingness to communicate thoughts and feelings, encourageactive participation, increase verbal proficiency, encourage use of imagination and creativity,encourage cooperation between students, and enhance listening skills.

\section{The Procedure of Story Completion}

The procedure of Story Completion is as follow

1. The teacher starts to tell a story

2. After a few sentences he/she stops narrating

3. Student A start to narrate from the point where the previous one stopped

4. Student B is supposed to add four to ten sentences

5. Each student can add new chracters, event, description, and so on until the story is finished (Adopted from Kayi, 2006)

\section{Conclusion}

Based on the previous description, it can be concluded that

1. Speaking is one of very important skills in English, where people are from different nations/countries can understand one another through this medium

2. EFL learners always face problems in learning English like speaking because there are some differences between English and mother tongues such as Bahasa Indonesia

3. Story completion plays important role in teaching speaking since it can challenge students to think critically and elaborate their ideas independently.

\section{References}

Al Hosni, Samira. 2014. Speaking Difficulties Encountered by Young EFL Learners. International Journal on Studies in English Language and Literature (IJSELL) Volume 2, Issue 6.

Ghiabi, Shima. 2014. Investigating the Effects of Story Retelling Technique as a Closed Task vs. Story- Completion as an Open Task on EFL Learners' Speaking. International Journal of English and Education. Volume 3. Issue 3.

Kayi, Hayriye. 2006. Teaching speaking: activities to promote speaking in a second language. The Internet TESL Journal, Vol.XII, No.11, November. Retrieved from http://iteslj. org/ Articles/KayiTeachingSpeaking.html on July 1, 2011. 
Lightbown, Patsy M and Spada, Nina. 2006. How Languages are Learned. Oxford University Press. Third edition.

Nunan, David. 2003. Practical English Language Teaching. NY:McGraw-Hill.

Thornbury, S., 2007. How to Teach Speaking. Harlow: Pearson Education Limited.

Ur, P., 1995. A Course in Language Teaching. Practice and Theory. Cambridge: Cambridge University Press. 